\title{
5S rRNA sequences of representatives of the genera Chlorobium, Prosthecochloris, Thermomicrobium, Cytophaga, Flavobacterium, Flexibacter and Saprospira and a discussion of the evolution of eubacteria in general
}

\author{
Hilde Van den Eynde, ${ }^{1}$ Yves Van de Peer, ${ }^{1}$ Jerome Perry ${ }^{2}$ and Rupert De Wachter ${ }^{1 *}$ \\ ${ }^{1}$ Departement Biochemie, Universiteit Antwerpen (UIA), Universiteitsplein 1, B-2610 Antwerpen, Belgium \\ ${ }^{2}$ Department of Microbiology, North Carolina State University, Box 7615, Raleigh, NC 27695-7615, USA
}

(Received 31 July 1989; revised 24 October 1989; accepted 26 October 1989)

\begin{abstract}
5S rRNA sequences were determined for the green sulphur bacteria Chlorobium limicola, Chlorobium phaeobacteroides and Prosthecochloris aestuarii, for Thermomicrobium roseum, which is a relative of the green non-sulphur bacteria, and for Cytophaga aquatilis, Cytophaga heparina, Cytophaga johnsonae, Flavobacterium breve, Flexibacter sp. and Saprospira grandis, organisms allotted to the phylum 'Bacteroides-CytophagaFlavobacterium' and relatives as determined by $16 \mathrm{~S}$ rRNA analyses. By using a clustering algorithm a dendrogram was constructed from these sequences and from all other known eubacterial 5S RNA sequences. The dendrogram showed differences, as well as similarities, with respect to results obtained by 16S RNA analyses. The 5S RNA sequences of green sulphur bacteria were closely related to one another, and to a cluster containing 5S RNA sequences from Bacteroides and its relatives, including Cytophaga aquatilis. 5S RNA sequences of all other representatives of the 'Bacteroides-Cytophaga-Flavobacterium' phylum as distinguished by 16S RNA analysis failed to group with Bacteroides and related clusters. On the basis of 5S RNA sequences, Thermomicrobium roseum clustered with Chloroflexus aurantiacus, as was expected from 16S RNA analysis.
\end{abstract}

\section{Introduction}

The order Chlorobiales (Gibbons \& Murray, 1978) consists of the families Chlorobiaceae (green sulphur bacteria) and Chloroflexaceae (gliding, filamentous, non-sulphur green bacteria). The members of these families share a number of unique properties. For instance, the light-harvesting pigments are located in typical chlorosome structures (Cohen-Bazire et al., 1964; Staehelin et al., 1978), and members of both families contain monogalactosyl diglyceride, but not phosphatidylethanolamine in their lipids. Conversely, the families differ in numerous features, such as the structure of their photosynthetic reaction centres (Olson \& Pierson, 1987) and their gliding ability. Furthermore, representatives of the Chlorobiaceae and Chloroflexaceae differ in their physiological and ecological properties. With the exception of Chloroherpeton thalassium (Gibson et al., 1984) and Chloroherpeton limnophilum (Eichler \& Pfennig, 1988), which demonstrate gliding motility, the Chlorobiaceae are non-motile, mesophilic, strictly anaerobic and obligately photo-autotrophic rods. In comparison,
Chloroflexus aurantiacus comprises gliding, thermophilic, facultatively chemo- or phototrophic filaments (Pierson \& Castenholz, 1974). Members of both families inhabit different ecological niches (Gorlenko, 1988). Moreover, analyses of $16 \mathrm{~S}$ rRNA oligonucleotide catalogues (Gibson et al., 1985) and full sequences (Oyaizu $e t$ al., 1987; Woese, 1987) have indicated a lack of phylogenetic relationship between the two families (Gibson et al., 1985). Whereas the genera Chlorobium (Cb.), Prosthecochloris and Chloroherpeton form a tight phylogenetic unit, the thermophilic Chloroflexus aurantiacus is distantly related to two non-photosynthetic genera, the thermophilic Thermomicrobium and the mesophilic Herpetosiphon (Gibson et al., 1985; Oyaizu et al., 1987). Phenotypically, the latter arrangement is not immediately obvious (Oyaizu et al., 1987). Indeed, the possession of unusual long-chain diols (Pond et al., 1986) is the only phenotypic characteristic that links Thermomicrobium roseum to Chloroflexus aurantiacus (Stackebrandt et al., 1988a), whereas Herpetosiphon giganteus and Chloroflexus aurantiacus possess similar carotenoids (Kleinig \& Reichenbach, 1977). From 16S RNA analy- 
ses, both families have been provisionally assigned the rank of 'phylum' (Woese et al., 1985). The lack of phylogenetic relationship between the two families is corroborated by lipopolysaccharide and peptidoglycan analyses (Jürgens et al., 1987; Meissner et al., 1987, 1988). The Chloroflexus-Thermomicrobium-Herpetosiphon phylum is one of the earliest branchings in eubacterial evolution (Oyaizu et al., 1987). As a consequence Chloroflexus, rather than the cyanobacteria, has been suggested to be the photosynthetic component of the stromatolites (Oyaizu et al., 1987). Another eubacterial phylum, termed 'Bacteroides-Cytophaga-Flavobacterium', made up of genera such as Bacteroides, Cytophaga (C.), Flexibacter, Saprospira, Sporocytophaga, Haliscomenobacter, Fusobacterium and Flavobacterium (Flv.) (Paster et al., 1985; Weisburg et al., 1985) has been suggested to bear a somewhat closer relationship to the phylum of green sulphur bacteria than to any of the remaining eubacterial phyla (Woese, 1987).

In order to compare results obtained with $16 \mathrm{~S}$ and 5S rRNA analyses, the 5S RNA sequences of $C b$. limicola, Cb. phaeobacteroides, Prosthecochloris aestuarii, Thermomicrobium roseum, Saprospira grandis, Flexibacter sp., Flv. breve, C. heparina, C. aquatilis and C. johnsonae were determined. Using weighted average pairgroup clustering, a phylogenetic tree was constructed from these sequences, together with some 282 other eubacterial 5S RNA sequences, representative of eight of the ten major phyla distinguished by Woese (1987).

\section{Methods}

Bacterial strains. The following strains were used: Chlorobium limicola DSM 249, Cb. phaeobacteroides DSM 266 ${ }^{\mathrm{T}}$ (T, type strain), Prosthecochloris aestuarii strain SK 413, Thermomicrobium roseum ATCC 27502 ${ }^{\mathrm{T}}$, Cytophaga aquatilis ATCC 29551 ${ }^{\mathrm{T}}, C$. heparina ATCC $13125^{\mathrm{T}}$, C. johnsonae DSM 425, Flavobacterium breve ATCC 14234, Flexibacter sp. DSM 527 and Saprospira grandis ATCC 23119'. These were obtained from the American Type Culture Collection (ATCC), Rockville, Md, USA, and from the Deutsche Sammlung von Mikroorganismen (DSM), Braunschweig, FRG. Culture conditions were as follows. $\mathrm{Cb}$. limicola, $\mathrm{Cb}$. phaeobacteroides and $P$. aestuarii were grown using the method described by Pfennig $\&$ Trüper (1981). T. roseum was obtained from Dr Robert F. Ramaley, Department of Biochemistry, University of Nebraska, USA, and grown at $65^{\circ} \mathrm{C}$ in a medium (pH 7.5) containing $\left(1^{-1}\right)$ tryptone (Difco), $1 \mathrm{~g}$, yeast extract (Difco), $1 \mathrm{~g}$, and mineral salts as described by Zarilla \& Perry (1984). C. aquatilis, $C$. heparina and $F$. breve were grown aerobically at $26^{\circ} \mathrm{C}$ in $8 \mathrm{~g}$ nutrient broth (Merck) $\mathrm{l}^{-1}$, pH 7.0. Flexibacter sp. was grown aerobically at $26^{\circ} \mathrm{C}$ in medium $(\mathrm{pH} 7 \cdot 2)$ containing $\left(1^{-1}\right)$ Casitone (Difco), $3 \mathrm{~g}$, and $\mathrm{CaCl}_{2} \cdot 2 \mathrm{H}_{2} \mathrm{O}, 1 \cdot 36 \mathrm{~g}$. The same culture conditions applied to $C$. johnsonae, with the exception that yeast extract (Difco; $1 \mathrm{~g} \mathrm{l}^{-1}$ ) was added to the medium. $S$. grandis was grown according to Lewin (1972). Cultivated organisms were harvested by centrifugation and stored by freezing or freeze-drying until needed.

Preparation of 5S RNA. Cells were ruptured using either glass beads and a cell mill (Willekens et al., 1986), or by grinding in a mortar with alumina (Van den Eynde et al., 1987). Sheared cells were then extracted with phenol (Willekens et al., 1986) in order to obtain the rRNA fraction. 5S RNA was prepared by PAGE, as previously described (Fang et al., 1982). 5S RNA was labelled at the $3^{\prime}$-terminus with cytidine $3^{\prime}, 5^{\prime}-\left[5^{\prime}-{ }^{2} \mathrm{P}\right]$ bisphosphate (Amersham), purified on $8 \%(\mathrm{w} / \mathrm{v})$ polyacrylamide gels, and subjected to partial chemical degradation (Peattie, 1979). Whenever necessary, partial enzymic degradation, as described previously (Dams et al., 1983), was used to confirm the nucleotide pattern. In the case of length heterogeneity, components of different chain length were sequenced separately. With $C b$. limicola, $C b$. phaeobacteroides, $P$. aestuarii, $C$. johnsonae, $C$. heparina, Flv. breve, $S$. grandis, Flexibacter sp. and $T$. roseum, electrophoresis of the partial degradation products on $8-20 \%(\mathrm{w} / \mathrm{v})$ polyacrylamide gels, kept at a constant temperature of $64^{\circ} \mathrm{C}$, proved sufficient to elucidate the entire sequence. In the case of $C$. aquatilis, the identity of the $5^{\prime}$-terminal nucleotide was confirmed by gel electrophoresis of enzymically degraded (Ap) ${ }_{4}$ A-extended, 5'-terminally labelled (Dams et al., 1983) 5S RNA.

Data analysis. Dendrograms were constructed by using a weighted pairgroup clustering algorithm, as described previously (Huysmans \& De Wachter, 1986; Dams et al., 1987). In short, a dissimilarity matrix that takes into account multiple and back mutations serves as the input for the tree-construction algorithm. A correction, to allow for the effects of unequal evolutionary rates along different eubacterial lineages, is incorporated. The standard deviations on the substitution terms of the computed dissimilarities are indicated by error fiags on all branching points of the resulting dendrogram.

\section{Results and Discussion}

Part of an alignment in which the newly determined sequences were aligned with approximately 600 5S RNA sequences of eubacterial, archaeobacterial, eukaryotic and organelle nature is included in Fig. 1. The complete alignment is available from the authors. Boxes superimposed on the alignment indicate putative doublestranded areas, according to a well-established secondary structure proposal (De Wachter et al., 1982). Starting from an alignment containing the 303 eubacterial 5S RNA sequences and supplemented with 10 cytoplasmic 5S RNA sequences from red algae to permit correction of unequal evolutionary rates, a dendrogram was constructed (Fig. 2). The majority of the sequences included are found in the biannual compilation of Wolters \& Erdmann (1988). The sequences are representative of eight of the ten major eubacterial phyla, as determined by 16S RNA analysis (Woese, 1987). When comparing the pattern deduced from 5S RNA sequence information with that based on 16S RNA analyses, a number of similarities and discrepancies become apparent. For example, no relationship was detected between plant mitochondrial 5S RNA sequences and the alpha subdivision of the recently installed (Stackebrandt et al., $1988 b$; formerly the purple bacteria and their relatives) class Proteobacteria. This might be an aberration of the tree-construction algorithm, due to the extremely fast rate at which mitochondrial genomes appear to be evolving. 


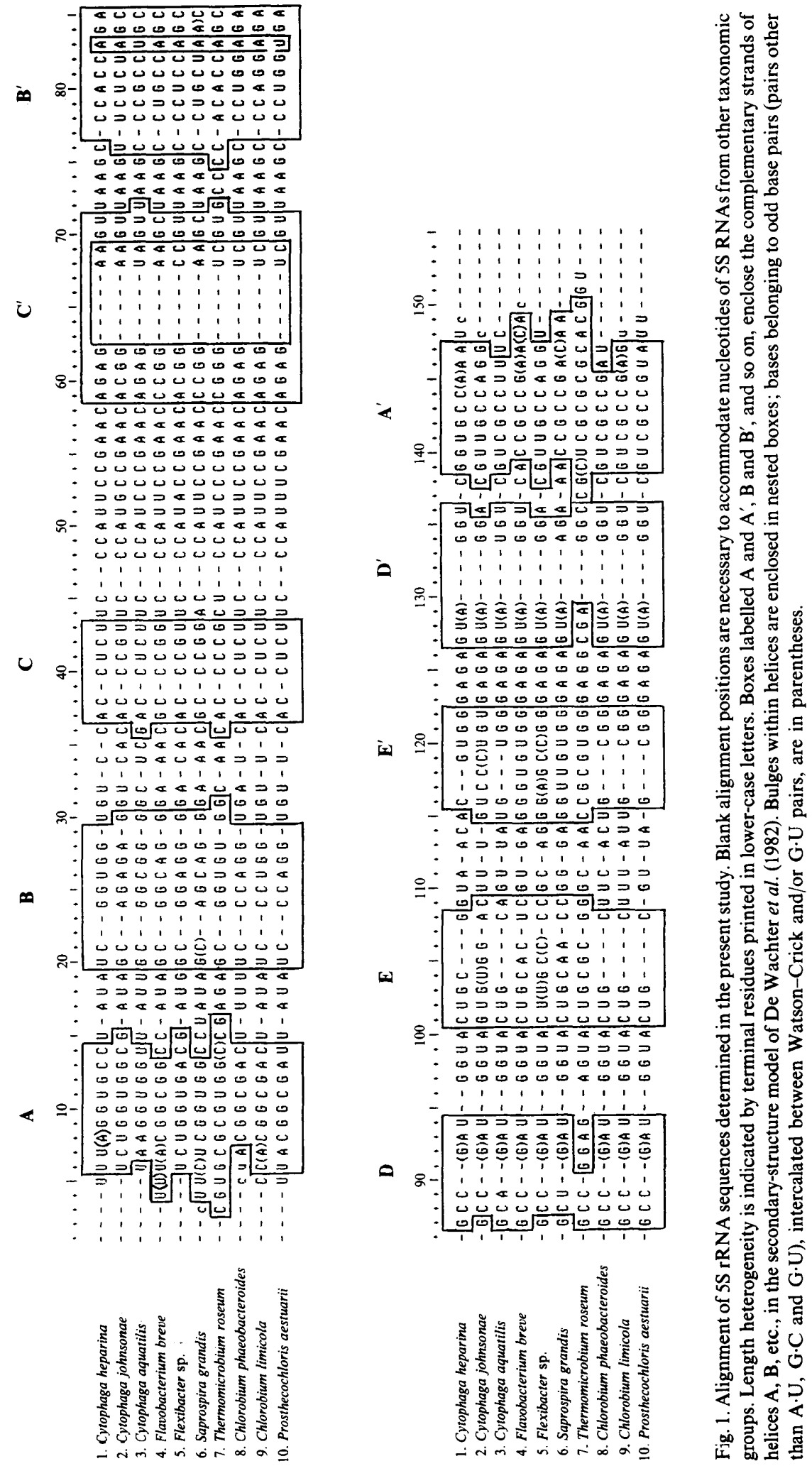




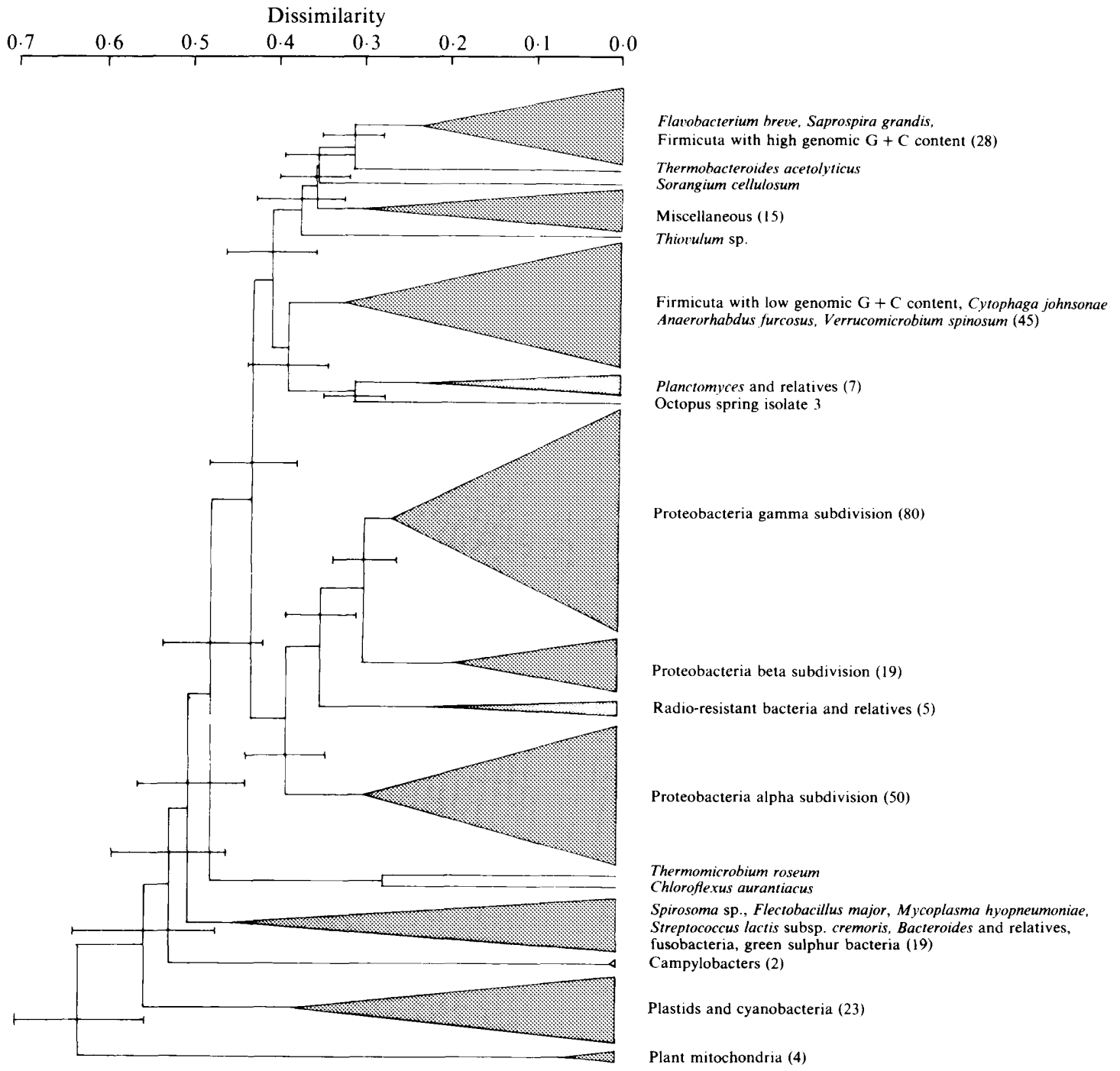

Fig. 2. Dendrogram constructed by weighted pairwise clustering of $5 S$ rRNA sequences from eubacteria and plant organelles. The complete dendrogram was constructed starting from an alignment that contained 303 eubacterial and organelle sequences available to us at present, supplemented with 10 cytoplasmic 5S RNA sequences from red algae (not shown). The latter were used as an external reference group, allowing for a correction for unequal evolutionary rates in different eubacterial lineages. Each major cluster is represented by an isosceles triangle with its top at the dissimilarity value corresponding to the first divergence within the cluster, and with a base proportional to the number of sequences enclosed (indicated in parentheses after the cluster name). Standard deviations on the substitution terms of the computed dissimilarities are indicated by bars. Details on composition and topology of the cluster harbouring 5S RNA sequences from Bacteroides and relatives and green sulphur bacteria, and the cluster denoted 'miscellaneous', are given in Fig. 3.

Gyanobacteria and plastids (Van den Eynde et al., 1988) are found as a monophyletic group, in accordance with the picture based on 16S RNA data. With 5S RNA, however, the cluster appears to branch off earlier in time than with 16S RNA. Furthermore, Campylobacter spp., on the basis of their 5S RNA sequence, exhibit no specific relationship to any of the eubacterial clusters (Fig. 2). Conversely, on the basis of 16S RNA sequences, a slight relationship of Campylobacter to the class Proteobacteria has been proposed (Lau et al., 1987).

The cluster that branches off next in Fig. 2 contains the majority of the 5S RNA sequences determined here. The cluster is defined by sequences from the Bacteroides-Cytophaga-Flavobacterium' group of organisms (Paster et al., 1985; Weisburg et al., 1985), and by sequences from green sulphur organisms (Gibson et al., 


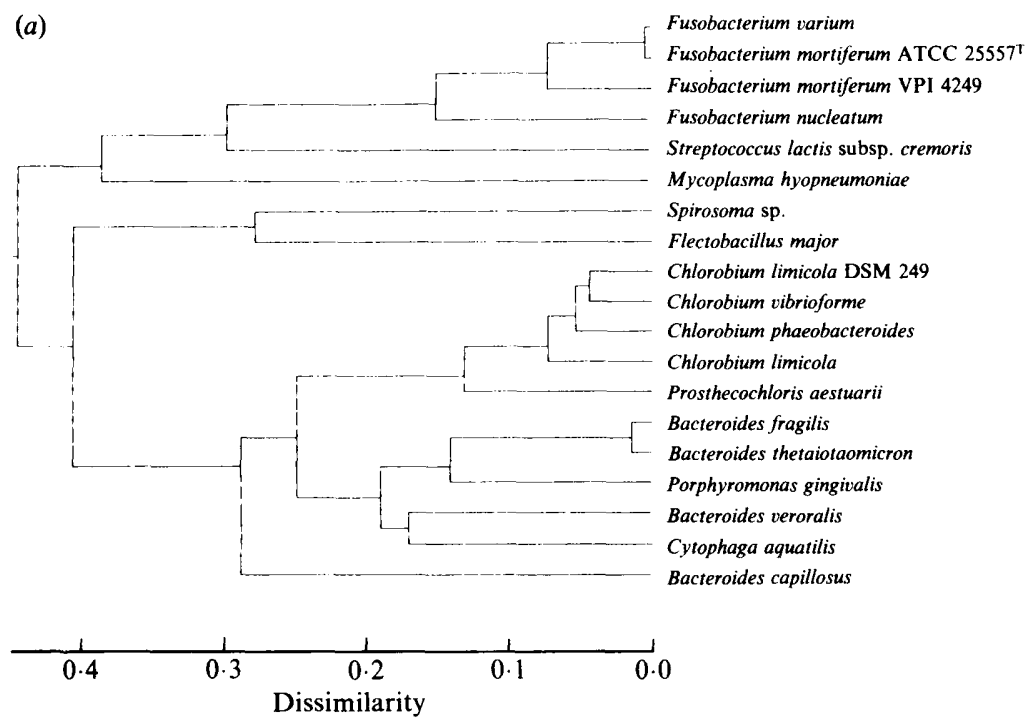

(b)

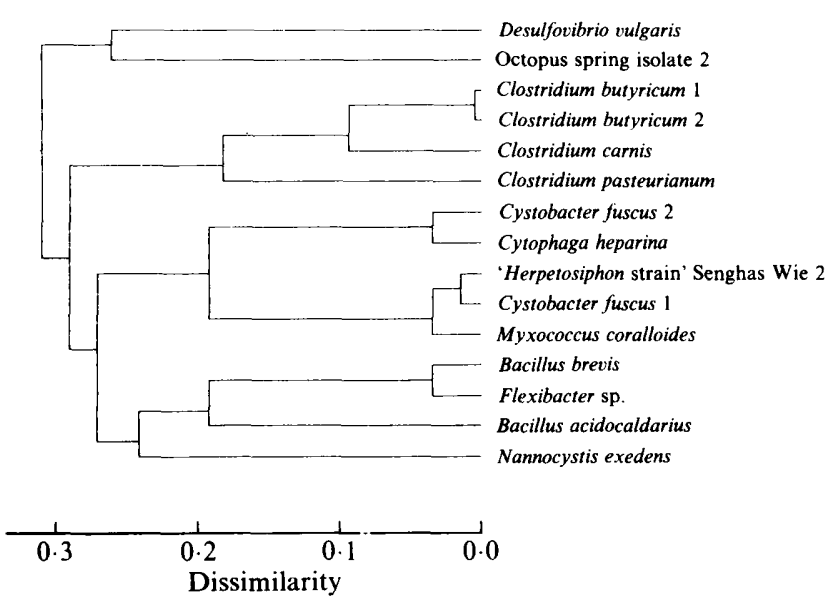

Fig. 3. (a) Detailed structure of the cluster containing the majority of the sequences determined in this study. Except for the sequences reported here, sequences were taken from Wolters \& Erdmann (1988) or are unpublished (N. R. Pace, personal communication). (b) Detailed structure of the cluster termed 'miscellaneous' in Fig. 2. Except for the sequences reported here, sequences were taken from Wolters \& Erdmann (1988), or are unpublished so far (H. Van den Eynde and others).

1985). A detailed picture of the cluster is presented in Fig. 3(a). In the cluster, 5S RNA sequences of Chlorobium and Prosthecochloris spp. are found closely related to one another, as was expected from 16S RNA analyses (Gibson et al., 1985). The 5S RNA sequences of $C b$. limicola DSM 249, Cb. phaeobacteroides and $C b$. vibrioforme (N. R. Pace, unpublished results), and of $C b$. limicola (Chumakov, 1987) are closely related.

The 5S RNA sequence of Prosthecochloris aestuarii was recovered next. As a whole, the green sulphur bacteria are associated with a cluster containing Bacteroides fragilis, B. thetaiotaomicron, Porphyromonas gingivalis and $B$. veroralis. This tendency towards a grouping of
Bacteroides and relatives with green sulphur bacteria has been observed previously, on the basis of both 16S RNA (Woese, 1987) and 5S RNA (Van den Eynde et al., 1989) analyses. With 16S RNA, however, the genus Fusobacterium is included in the 'Bacteroides'-like cluster, whereas with 5S RNA Fusobacterium is only peripherally related to the Bacteroides-green sulphur bacteria assemblage (Van den Eynde et al., 1989). Furthermore, with 16S RNA sequences, Flv. breve, Flexibacter sp., $S$. grandis, $C$. heparina and $C$. johnsonae are recovered with the genus Bacteroides to form the so-called 'BacteroidesCytophaga-Flavobacterium' phylum. That this is not the case with 5S RNA is documented below. The 5S RNAs 
of Streptococcus lactis subsp. cremoris and of Mycoplasma hyopneumoniae were recovered, atypically, close to the Fusobacterium cluster, whereas they were expected to group with mycoplasmata and lactobacilli 5S RNA sequences.

The 5S RNA sequences from two out of three representative species of the phylum of green nonsulphur bacteria and relatives, namely Chloroflexus aurantiacus (D. A. Stahl, unpublished results) and Thermomicrobium roseum, were found (Fig. 2) to bear a specific relationship to one another, in accordance with the picture derived from 16S RNA analyses (Oyaizu et al., 1987). The suggested ancient nature of the phylum of green non-sulphur bacteria and relatives (Oyaizu et al., 1987) was not corroborated by 5S RNA analysis. In fact, both the cyanobacteria-plastid cluster and the cluster containing the green sulphur bacteria branched off earlier than the Chloroflexus cluster (Fig. 2). The results presented in this paper thus fail to affirm the proposal (Oyaizu et al., 1987) of Chloroflexus being the photosynthetic component of the stromatolites. The 5S RNA of 'Herpetosiphon strain' Senghas Wie 2 (Van den Eynde et al., 1987), originating from exactly the same strain (Senghas \& Lingens, 1985) as was used for 16S RNA analysis, was not, contrary to $16 \mathrm{~S}$ RNA results, recovered in close association with Chloroflexus and Thermomicrobium 5S RNA. Instead, the 'Herpetosiphon strain' Senghas Wie 2 sequence grouped with a cluster termed 'miscellaneous' in Fig. 2, and presented in detail in Fig. 3(b). Apart from the 'Herpetosiphon strain' Senghas Wie 2 sequence and a number of sequences from low $\mathrm{G}+\mathrm{C}$ content Firmicuta, sequences from organisms belonging to the Proteobacteria delta group, from C. heparina and from Flexibacter sp. were scattered throughout this cluster. Thus, regarding the assignment of strain Senghas Wie 2 to the phylum of green sulphur bacteria and their relatives (Senghas \& Lingens, 1985), and the connected suggestion for an assignment of the strain to the genus Herpetosiphon (Gibson et al., 1985; Woese et al., 1985), we urge caution. In any case, in the original paper of Senghas \& Lingens (1985), the strain was set well apart from the genus Herpetosiphon on the basis of physiological differences and of differences in fatty acid composition and in DNA G + C content.

As for the Proteobacteria, in agreement with the findings based on 16S RNA, the subdivisions alpha, beta and gamma were recovered intact, and in close connection with one another. However, with 5S RNA analysis, the alpha subdivision was severed from the beta and gamma clusters by a group containing radio-resistant organisms such as Deinococcus and their relatives. We can see no evidence for the existence of a fourth subdivision, delta, of the class Proteobacteria (Woese, 1987; Stackebrandt et al., 1988b), since organisms of the delta subgroup (H. Van den Eynde and others, unpublished) that were examined had 5S RNA sequences that grouped with, or, in the case of the Sorangium cellulosum 5S RNA, close to the miscellaneous cluster (Figs 2 and $3 b)$.

Rather more in accordance with results based on 16S RNA sequencing is the occurrence in Fig. 2 of a cluster harbouring the genera Planctomyces, Pirellula, Gemmata and Isosphaera, which all lack peptidoglycan.

The phylum of Gram-positive organisms, or Firmicuta, a monophyletic grouping with four subdivisions according to 16S RNA analysis (Woese, 1987), showed a different arrangement on the basis of 5S RNA analysis, as can be seen from Fig. 2. The two most important subdivisions, namely Firmicuta with low, and Firmicuta with high DNA G $+C$ contents, have a large number of representatives in the 5S RNA data bank. Results from 16S RNA analysis were corroborated to a certain extent by 5S RNA sequence data, although some of the 5S RNA sequences of Gram-positive organisms were recovered in unexpected places in the tree. Examples are the occurrence of some sequences of clostridia and bacilli, Firmicuta of low DNA $\mathrm{G}+\mathrm{C}$ content, in the aforementioned 'miscellaneous' cluster (Fig. 3b), a cluster more closely related to the Firmicuta with high rather than to those with low DNA G + C content. Also unexpected, was the occurrence of the 5S RNA of Flv. breve and of Saprospira grandis among the Firmicuta with high DNA G + C content, and the occurrence of Cytophaga johnsonae, Anaerorhabdus furcosus (Van den Eynde et al., 1989) and Verrucomicrobium spinosum (Bomar \& Stackebrandt, 1987) 5S RNAs with those of Firmicuta with a low genomic $\mathrm{G}+\mathrm{C}$ content. 16S RNA studies have previously shown the relatedness of the Gram-negative genera Selenomonas, Sporomusa and Megasphaera, to the Firmicuta and relatives phylum (Stackebrandt et al., 1985). 16S RNA analysis showed these genera to be closely related, and to constitute one of the four subdivisions of the phylum (Woese, 1987). In contrast, several 5S RNA sequences from Gram-negative species, were scattered throughout the low and high $\mathrm{G}+\mathrm{C}$ content subdivisions of the Gram-positive cluster, a clear discrepancy with results obtained by 16S RNA analysis. Moreover, since we chose exactly the same strains as were used for 16S RNA analysis (Paster et al., 1985), in the case of C. johnsonae, C. heparina, Flv. breve and $S$. grandis 5S RNA, an association with the 'Bacteroides-Cytophaga-Flavobacterium' cluster, and not with the Gram-positive organisms, was most strongly expected. That this was not the case makes the observed discrepancy even more unusual. Moreover, 5S RNA analysis did not corroborate the ancient line of descent proposed for Verrucomicrobium spinosum by Albrecht $e t$ al. (1987). 
We cannot offer a clearcut explanation for the differences revealed by analyses of 5S and 16S RNA sequences. The nature of the 5S RNA molecule, as opposed to the 16S RNA molecule, cannot, in our opinion be held responsible. Although 5S RNA is much smaller than 16S RNA (an average of 120 nucleotides for 5S RNA against an average of about 1550 nucleotides for eubacterial 16S RNA), 5S RNA is far more conserved than 16S RNA and has had to suffer less from extensive insertion- and/or deletion events. The alignment procedure with 5S RNA is thus much less prone to error than is the case with 16S RNA. Furthermore, it is not solely discrepancies that are encountered when results from 5S RNA sequence analysis are compared to those obtained using 16S RNA: many features of the 16S RNA evolutionary picture corroborated fairly well by analyses of 5S RNA sequences. The part played by unequal eubacterial evolutionary rates, is thought to be limited due to the application of a correction procedure for this phenomenon. In view of the conflicting results obtained with 5S RNA and 16S RNA, we believe that a renewed and thorough investigation of the phylogenetic interrelationships of the organisms assigned to the 'Bacteroides-Cytophaga-Flavobacterium' is needed. Questions can also be raised regarding the extent to which the use of different tree-construction algorithms influences the inferred evolutionary picture. The differing results obtained using 16S RNA and 5S RNA as molecular tools for studying eubacterial evolution suggests, that the use of additional molecular clocks, such as 23S rRNA, may be required in order to arrive at a consensus picture of eubacterial evolution.

We thank Dr N. Pfennig for providing cells of Chlorobium limicola, Chlorobium phaeobacteroides and Prosthecochloris aestuarii, and Drs N. R. Pace and D. A. Stahl for providing unpublished data. Our research was subsidized in part by a grant from the 'Fonds voor Kollektief Fundamenteel Onderzoek'. Y. VdP is holder of a grant from the 'Instituut tot aanmoediging van het Wetenschappelijk Onderzoek In Nijverheid en Landbouw'.

\section{References}

Albrecht, W., Fischer, A., Smida, J. \& Stackebrandt, E. (1987). Verrucomicrobium spinosum, a eubacterium representing an ancient line of descent. Systematic and Applied Microbiology 10, 57-62.

BomaR, D. \& StackebrandT, E. (1987). 5S rRNA sequences from Nitrobacter winogradskyi, Caulobacter crescentus, Stella humosa and Verrucomicrobium spinosum. Nucleic Acids Research 15, 9597.

Chumakov, K. M. (1987). Evolution of nucleotide sequences. Soviet Scientific Reviews. Section D. Physicochemical Biology 7, 51-94.

Cohen-Bazire, G., Pfennig, N. \& Kunisawa, R. (1964). The fine structure of green bacteria. Journal of Cell Biology 22, 207-225.

DAMS, E., VANDENBERGHE, A. \& DE WACHTER, R. (1983). Sequences of the $5 \mathrm{~S}$ rRNAs of Azotobacter vinelandii, Pseudomonas aeruginosa and Pseudomonas fluorescens with some notes on 5S RNA secondary structure. Nucleic Acids Research 11, 1245-1252.
Dams, E., Yamada, T., De Baere, R., Huysmans, E., Vandenberghe, A. \& DE WACHTER, R. (1987). Structure of 5S rRNA in actinomycetes and relatives and evolution of eubacteria. Journal of Molecular Evolution 25, 255-260.

De Wachter, R., Chen, M.-W. \& Vandenberghe, A. (1982). Conservation of secondary structure in 5S ribosomal RNA: a uniform model for eukaryotic, eubacterial, archaebacterial and organelle sequences is energetically favourable. Biochimie 64, 311329.

EICHLER, B. \& PFENNIG, N. (1988). A new green sulphur bacterium from a freshwater pond. In Green Photosynthetic Bacteria, pp. 233235. Edited by J. M. Olson, J. G. Ormerod, J. Amesz, E. Stackebrandt \& H. G. Trüper. New York \& London: Plenum Press.

FANG, B.-L., De Baere, R., VANDENBerghe, A. \& De WaChter, R. (1982). Sequences of three molluscan 5S ribosomal RNAs confirm the validity of a dynamic secondary structure model. Nucleic Acids Research 10, 4679-4685.

Gibbons, N. E. \& Murray, R. G. E. (1978). Proposals concerning the higher taxa of bacteria. International Journal of Systematic Bacteriology 28, 1-6.

Gibson, J., Pfennig, N. \& Waterbury, J. B. (1984). Chloroherpeton thallassium gen. nov. et sp. nov., a non-filamentous, flexing and gliding green sulphur bacterium. Archives of Microbiology 138, 96101.

Gibson, J., Ludwig, W., Stackebrandt, E. \& Woese, C. R. (1985). The phylogeny of the green photosynthetic bacteria: absence of a close relationship between Chlorobium and Chloroflexus. Systematic and Applied Microbiology 6, 152-156.

GorLENKo, V. M. (1988). Ecological niches of green sulphur and gliding bacteria. In Green Photosynthetic Bacteria, pp. 257-267. Edited by J. M. Olson, J. G. Ormerod, J. Amesz, E. Stackebrandt \& H. G. Trüper. New York \& London: Plenum Press.

HuYsmans, E. \& DE WACHTER, R. (1986). The distribution of 5S ribosomal RNA sequences in phenetic hyperspace. Implications for eubacterial, eukaryotic, archaebacterial and early biotic evolution. Endocytobiosis and Cell Research 3, 133-155.

JÜrgens, U. J., MeISSner, J., Fischer, U., KöNIG, W. A. \& WECKESSER, J. (1987). Ornithine as a constituent of the peptidoglycan of Chloroflexus aurantiacus, diaminopimelic acid in that of Chlorobium vibrioforme f. thiosulfatophilum. Archives of Microbiology 148, 72-76.

KleiniG, H. \& Reichenbach, H. (1977). Carotenoid glucosides and menaquinones from the gliding bacterium Herpetosiphon giganteus $\mathrm{Hp}$ a2. Archives of Microbiology 112, 307-310.

Lau, P. P., DeBrunner-Vossbrinck, B., Dunn, B., Miotto, K., MacDonell, M. T., Rollins, D. M., Pillidge, C. J., Hespell, R. B., Colwell, R. R., Sogin, M. L. \& Fox, G. E. (1987). Phylogenetic diversity and position of the genus Campylobacter. Systematic and Applied Microbiology 9, 231-238.

LEwIN, R. A., (1972). Growth and nutrition of Saprospira grandis Gross (Flexibacterales). Canadian Journal of Microbiology 18, 361-365.

MeisSNer, J., Fischer, U. \& WeCKesser, J. (1987). The lipopolysaccharide of the green sulphur bacterium Chlorobium vibrioforme $\mathrm{f}$. thiosulfatophilum. Archives of Microbiology 149, 125-129.

Meissner, J., Krauss, J. H., JÜrgens, U. J. \& WeCKesSer, J. (1988). Absence of a characteristic cell wall lipopolysaccharide in the phototrophic bacterium Chloroflexus aurantiacus. Journal of Bacteriology 170, 3213-3216.

Olson, J. M. \& Pierson, B. K. (1987). Origin and evolution of photosynthetic reaction centers. Origins of Life 17, 419-430.

Oyaizu, H., DeBrunner-Vossbrinck, B., Mandelco, L., Studier, J. A. \& WoEsE, C. R. (1987). The green non-sulphur bacteria : a deep branching in the eubacterial line of descent. Systematic and Applied Microbiology 9, 47-53.

Paster, B. J., Ludwig, W., Weisburg, W. G., Stackebrandt, E., Hespell, R. B., Hahn, C. M., Reichenbach, H., Stetter, K. O. \& WOESE, C. R. (1985). A phylogenetic grouping of the Bacteroides, cytophagas, and certain flavobacteria. Systematic and Applied Microbiology 6, 34-42.

PeatTie, D. A. (1979). Direct chemical method for sequencing RNA. Proceedings of the National Academy of Sciences of the United States of America 76, 1760-1764. 
Pfennig, N. \& Trüper, H. G. (1981). Isolation of members of the families Chromatiaceae and Chlorobiaceae. In The Prokaryotes. $A$ Handbook on Habitats, Isolation and Identification of Bacteria, pp. 279-289. Edited by M. P. Starr, H. Stolp, H. G. Trüper, A. Balows \& H. G. Schlegel. Berlin: Springer Verlag.

Pierson, B. K. \& Castenholz, R. W. (1974). A phototrophic gliding filamentous bacterium of hot springs, Chloroflexus aurantiacus, gen. and sp. nov. Archives of Microbiology 100, 5-24.

Pond, J. L., Langworthy, T. A. \& Holzer, G. (1986). Long-chain diols: a new class of membrane lipids from a thermophilic bacterium. Science 231, 1134-1136.

Senghas, E. \& Lingens, F. (1985). Characterization of a new Gramnegative filamentous bacterium isolated from bulking sludge. Applied Microbiology and Biotechnology 21, 118-124.

Stackebrandt, E., Pohla, H., Kroppenstedt, R., Hippe, H. \& WOESE, C. R. (1985). 16S rRNA analysis of Sporomusa, Selenomonas, and Megasphaera: on the phylogenetic origin of Gram-positive eubacteria. Archives of Microbiology 143, 270-276.

StaCkebrandT, E., EMbley, M. \& Weckesser, J. (1988a). Phylogenetic, evolutionary, and taxonomic aspects of phototrophic eubacteria. In Green Photosynthetic Bacteria, pp. 201-215. Edited by J. M. Olson, J. G. Ormerod, J. Amesz, E. Stackebrandt \& H. G. Trüper. New York \& London: Plenum Press.

Stackebrandt, E., Murray, R. G. E. \& Trüper, H. G. (1988b). Proteobacteria classis nov., a name for the phylogenetic taxon that includes the "purple bacteria and their relatives". International Journal of Systematic Bacteriology 38, 321-325.

Staehelin, L. A., Golecki, J. R., Fuller, R. C. \& Drews, G. (1978). Visualization of the supramolecular architecture of chlorosomes (chlorobium type vesicles) in freeze-fractured cells of Chloroflexus aurantiacus. Archives of Microbiology 119, 269-277.
Van den Eynde, H., STackebrandt, E. \& DE Wachter, R. (1987). The structure of the $5 \mathrm{~S}$ ribosomal RNA of a member of the phylum of green non-sulphur bacteria and relatives. FEBS Letters 213, 301303.

Van den Eynde, H., De Baere, R., De Roeck, E., Van de Peer, Y., Vandenberghe, A., Willekens, P. \& DE Wachter, R. (1988). The $5 S$ ribosomal RNA sequences of a red algal rhodoplast and a gymnosperm chloroplast. Implications for the evolution of plastids and cyanobacteria. Journal of Molecular Evolution 27, 126-132.

Van den Eynde, H., De Baere, R., Shah, H. N., Gharbia, S. E., Fox, G. E., Michalik, J., Van de Peer, Y. \& De Wachter, R. (1989). 5S ribosomal ribonucleic acid sequences in Bacteroides and Fusobacterium: evolutionary relationships within these genera and among eubacteria in general. International Journal of Systematic Bacteriology $39,78-84$.

Weisburg, W. G., Oyaizu, Y., Oyaizu, H. \& Woese, C. R. (1985). Natural relationships between bacteroides and flavobacteria. Journal of Bacteriology 164, 230-236.

Willekens, P., Huysmans, E., Vandenberghe, A. \& DE Wachter, R. (1986). Archaebacterial 5S ribosomal RNA: nucleotide sequence in two methanogen species, secondary structure models, and molecular evolution. Systematic and Applied Microbiology 7, 151-159.

Woese, C. R. (1987). Bacterial evolution. Microbiological Reviews 51, $221-271$.

Woese, C. R., Stackebrandt, E., Macke, T. J. \& Fox, G. E. (1985). A phylogenetic definition of the major eubacterial taxa. Systematic and Applied Microbiology 6, 143-151.

Wolters, J. \& ErdmanN, V. A. (1988). Compilation of 5S rRNA and 5S rRNA gene sequences. Nucleic Acids Research 16, rl-r70.

ZARILlA, K. A. \& PeRry, J. J. (1984). Thermoleophilum album gen. nov. and sp. nov., a bacterium obligate for thermophily and n-alkane substrates. Archives of Microbiology 137, 286-290. 